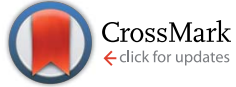

Cite this: RSC Adv., 2014, 4, 58083

DOI: $10.1039 / c 4 r a 90038 c$

www.rsc.org/advances

\section{Correction: Nano-scale morphological analysis of graphene-rubber composites using 3D transmission electron microscopy}

\author{
Amit Das, ${ }^{\text {ab }}$ Regine Boldt, ${ }^{a}$ René Jurk, ${ }^{a}$ Dieter Jehnichen, ${ }^{a}$ Dieter Fischer, ${ }^{a}$ \\ Klaus Werner Stöckelhuber ${ }^{\star a}$ and Gert Heinrich ${ }^{\text {ac }}$
}

Correction for 'Nano-scale morphological analysis of graphene-rubber composites using 3D transmission electron microscopy' by Amit Das et al., RSC Adv., 2014, 4, 9300-9307.

The authors wish to amend the authorship of this article by adding an author, Daniel Wolf. The author list should be as follows: Amit Das $^{\mathrm{a}, \mathrm{b}}$, Regine Boldt ${ }^{\mathrm{a}}$, Daniel Wolf ${ }^{\mathrm{d}}$, René Jurk ${ }^{\mathrm{a}}$, Dieter Jehnichen ${ }^{\mathrm{a}}$, Dieter Fischer ${ }^{\mathrm{a}}$, Klaus Werner Stöckelhuber*a ${ }^{*}$, and Gert Heinrich $^{\mathrm{a}, \mathrm{c}}$

${ }^{a}$ Leibniz-Institut für Polymerforschnung, Dresden e. V., Hohe Straße 6, D-01069 Dresden, Germany. E-mail: stoeckelhuber@ipfdd.de; Fax: +49 3514658 362; Tel: +49 3514658 579;

${ }^{\mathrm{b}}$ Tampere University of Technology, Korkeakoulunkatu 16, Fi-33101 Tampere, Finland

${ }^{\mathrm{c}}$ Technische Universität Dresden, Institut für Werkstoffwissenschaft, D-01069 Dresden, Germany

${ }^{\mathrm{d}}$ Technische Universität Dresden, Institute of Structure Physics, Triebenberg Lab, D-01062 Dresden, Germany

The Acknowledgements section is therefore also amended:

Acknowledgements

The authors thank the German Federal Ministry of Education and Research (BMBF) for financial support of the project ELAGRA within the framework of the BMBF program "Werkstoffinnovationen für Industrie und Gesellschaft"- WING. - Grant number: 03X0110B. Manfred Klüppel, Markus Möwes and Christian W. Karl, DIK Hanover, are acknowledged for helpful and fruitful discussions.

The Royal Society of Chemistry apologises for these errors and any consequent inconvenience to authors and readers.

\footnotetext{
${ }^{a}$ Leibniz-Institut für Polymerforschnung, Dresden e. V., Hohe Straße 6, D-01069 Dresden, Germany. E-mail: stoeckelhuber@ipfdd.de; Fax: +493514658 $362 ;$ Tel: +49 3514658 579 